\title{
Sistem Informasi Pelatihan Berbasis Digital (Studi Kasus: PPK LPPM Universitas Terbuka)
}

\author{
${ }^{1}$ Dedy Juniadi, ${ }^{2}$ Erman Arif, ${ }^{3}$ Syafiqoh Nurhayati \\ ${ }^{1,3}$ Perpajakan, FHISIP, Universitas Terbuka \\ ${ }^{2}$ Sistem Informasi, FST, Universitas Terbuka \\ Universitas Terbuka \\ Jalan Cabe Raya, Pondok Cabe, Pamulang, Tangerang Selatan 15418, Banten, Indonesia \\ Email: dedy.juniadi@ecampus.ut.ac.id \\ Article History: \\ Received: 08-Nopember-2020; Received in Revised: 10-Nopember-2020; Accepted: 17-Nopember-2020
}

\begin{abstract}
ABSTRAK
Aplikasi pelatihan dan workshop merupakan sistem informasi berbasis website yang memberikan informasi mengenai adanya acara seminar baru yang akan diselenggarakan disertai dengan pendaftaran seminar tersebut. Peserta yang mendaftar merupakan anggota yang telah melakukan registrasi dari sistem informasi ini. Panitia seminar dibentuk oleh kepala unit dibantu oleh staff dan adminnya dengan membuatkan akun login ke sistem. (1) Sesuai dengan jadwal kerja di Lembaga Penelitian dan Pengabdian kepada Masyarakat (LPPM) Universitas Terbuka, khususnya di unit Pusat Penelitian dan Keilmuan (PPK) LPPM melakukan kegiatan sebanyak 55 (lima puluh lima) per tahun dimana disetiap kegiatan, peserta yang mengikuti pelatihan akan mendapatkan sertifikat, (2) Proses pembuatan dan validasi sertifikat masih menggunakan cara manual sehingga membutuhkan banyak waktu dan tenaga yang diperlukan. (3) Atas dasar proses yang lambat tersebut maka Tim peneliti menganggap Pusat Penilitian dan Keilmuan (PPK) LPPM perlu mengembangkan sebuah aplikasi berbasis website agar dapat menjadi sistem informasi untuk mendapatkan sertifikat yang cepat dan tepat di lingkungan Universitas Terbuka. (4) Penelitian menggunakan skema penugasan dan multi years selama tiga tahun. (5) Keluaran dari penelitian penugasan ini adalah artikel, HKI, dan prototipe aplikasi. Tipe penelitian yang digunakan adalah deskriptif-kualitatif, dengan format studi kasus yang mana bertujuan untuk melukiskan atau menggambarkan, memberikan infromasi dan penjelasan tentang masalah yang diteliti berdasarkan observasi dan wawancara mendalam terhadap informan. Penelitian ini mengunakan dua teknik pengumpulan data, yakni data primer, dan data sekunder. Pada tahap analisis, kami akan menggali informasi dengan cara purposive sampling dengan memilih informan yaitu ketua lembaga LPPM, Kepala Unit PPK LPPM, dan dosen Univeritas Terbuka.
\end{abstract}

Kata kunci: e-Sertifikat; Aplikasi Website; Sistem Informasi Manajemen.

ABSTRACT

The training and workshop application is a website-based information system that provides information about new seminars held along with registration for the seminar. Participants who register are members who have registered from this information system. The seminar committee is formed by the unit head assisted by the staff and admin by creating a login account. (1) By the work schedule at the Institute for Research and Community Service (LPPM), the Universitas Terbuka, particularly in the Research and Scientific Center (PPK) unit, the LPPM carries out as many as 55 (fifty-five) activities per year wherein each activity, participants take part in the training. will get a certificate, (2) The process of making and validating a certificate is still manual, so it requires a lot of time and 
effort. (3) Based on this slow process, the research team considers the LPPM Center for Research and Science (PPK) to develop a website-based application to become an information system for obtaining fast and valid certificates in the Universitas Terbuka environment. (4) The study used an assignment scheme and multi-years for three years. (5) The outputs of this research assignment are articles, IPR, and application prototypes. The type of research used is descriptive-qualitative, with a case study format that aims to describe or describe, provide information, and explain the problem under study based on observations and in-depth interviews with informants. This study uses two data collection techniques, namely primary data and secondary data. In the analysis stage, we will dig up information using purposive sampling by selecting informants, namely the head of the LPPM institution, the Head of the PPK LPPM Unit, and the lecturers of the Universitas Terbuka.

Keywords: e-Certificate; Website Application; Management Information System.

\section{PENDAHULUAN}

Aplikasi pelatihan merupakan sistem informasi berbasis web yang memberikan informasi mengenai adanya acara seminar baru yang akan diselenggarakan disertai dengan pendaftaran seminar tersebut. Peserta yang mendaftar merupakan anggota yang telah melakukan registrasi dari sistem informasi ini. Panitia seminar dibentuk oleh ketua unit dibantu oleh staff dan adminnya dengan membuatkan akun login ke sistem. Untuk meningkatkan mutu dan kualitas dari peneliti dalam perkembangan teknologi informasi dan penelitian, banyak kegiatan yang membutuhkan aplikasi pengolah data kegiatan, pendaftaran kegiatan, dan penyeleksi data kegiatan serta mendapatkan esertifikat secara mudah setelah mengikuti pelatihan. Pada saat pendaftaran peserta kegiatan membutuhkan waktu yang lama jika masih dilakukan secara manual sehingga tidak efektif dan efisien. Berdasarkan latar belakang di atas, Tim peneliti menganggap PPK LPPM perlu mengembangkan sebuah aplikasi berbasis website untuk dapat dijadikan sistem informasi bagi dosen/peneliti untuk mendapatkan informasi pelatihan dan informasi kegiatan seminar pendidikan.

\section{METODE}

Tipe penelitian yang digunakan adalah Deskriptif-Kualitatif, dengan format studi kasus yang mana bertujuan untuk melukiskan atau menggambarkan, memberikan infromasi dan penjelasan tentang masalah yang diteliti berdasarkan observasi dan wawancara mendalam terhadap informan.

Penelitian ini mengunakan dua teknik pengumpulan data, yakni :

Data Primer, yaitu data yang diperoleh melalui penelitian lapangan secara langsung menemui para informan yang dilakukan dua cara, yaitu :

- Observasi, yaitu pengumpulan data dengan mengamati obyek penelitian untuk memperoleh informasi atau yang diperlukan.

- Wawancara (Indepth Interviews), yaitu mengajukan pertanyaan-pertanyaan secara mendalam kepada responden yang erat kaitannya dengan permasalahan dan menggunakan pendoman wawancara.

Data Sekunder, yaitu data yang diperoleh melalui penelitian lapangan secara tidak langsung.

Langkah yang diambil dalam teknik analisis data dalam penelitian ini ialah menggunakan Analisis Data Kualitatif oleh Model Interaktif Miles \& Huberman (1992).

\section{Jenis Metode Pengembangan Perangkat Lunak}

Metode yang digunakan untuk membangun sistem informasi pelatihan berbasis digital ini adalah menggunakan metode Waterfall Menurut Pressman (2015:42) seperti terlihat pada Gambar 2. Terdapat 5 tahap yang harus dilalui dalam menggunakan metode ini yaitu: Analisis, Desain, Implementasi, Testing dan Pemeliharaan. Pada penelitian ini, kami menyadur metode waterfall tersebut hingga tahap ke-4, dikarenakan program yang dihasilkan adalah prototype, dengan demikian tidak ada maintenance karena belum digunakan. 


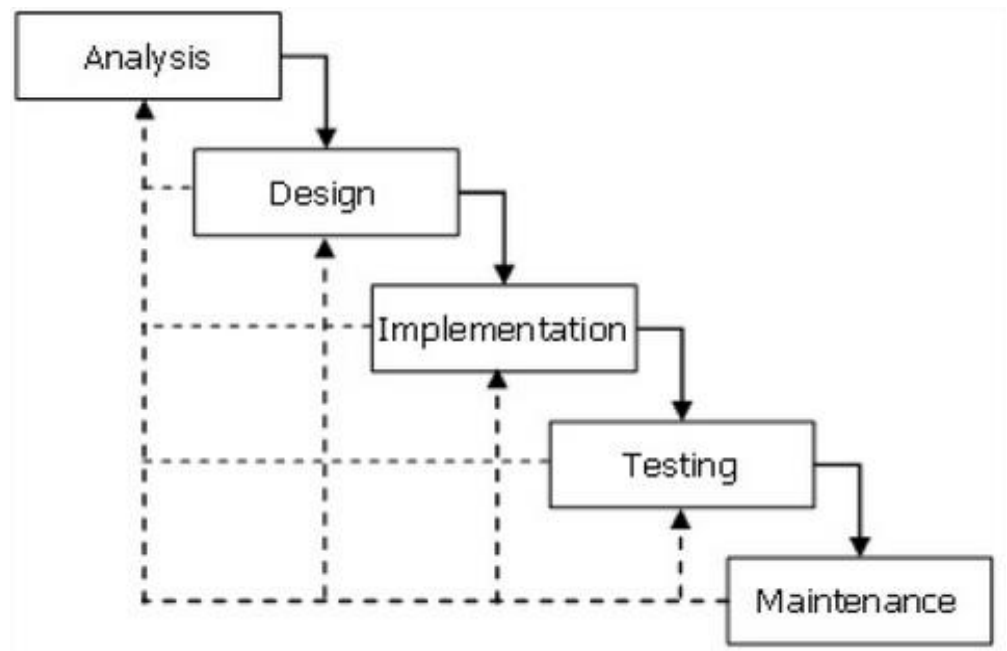

Gambar 1. Tahapan SDLC

\section{Analisis}

Pada tahap analisis, kami akan menggali informasi dengan cara purposive sampling dengan memilih informan yaitu ketua lembaga LPPM, Kepala Unit PPK LPPM, dan dosen Univeritas Terbuka melalui wawancara, observasi ke lapangan, serta studi litelatur. Berdasarkan penggalian informasi tersebut maka kami akan menganalisis berbagai kemungkinan baik dan buruknya pembangunan sistem informasi ini, sehingga kami akan menanggulanginya sesuai dengan kebutuhan dilapangan.

\section{Desain}

Desain yang dilakukan berasal dari informasi hasil analisis yang telah didapatkan, sehingga kami mampu mendesain sistem informasi atas karya publikasi dosen/peneliti ini, secara garis besar pada tahapan desain ini terbagi menjadi empat bagian yaitu:

1. Konseptual Sistem

2. Database

3. Alur Kinerja Sistem

4. Tampilan Sistem (Mockup)

\section{Implementasi}

Implementasi yang dilakukan, dibantu dengan perangkat lunak, perangkat keras, dan jaringan web hosting dan domain. Dengan rincian sebagai berikut:

\section{Testing}

Testing dilakukan untuk mengetahui bug yang terdapat pada sistem, metode testing yang dapat digunakan yaitu metode black box testing ataupun white box testing, untuk mengetahui kinerja dan kualitas dari sistem yang dibangun.

\section{HASIL DAN PEMBAHASAN}

\subsection{Hasil}

Hasil kegiatan setelah melakukan analisis sesuai dengan kebutuhan maka didapatkan beberapa hasil yaitu rancangan struktur sistem, rancangan database, dan rancangan Mockup tampilan aplikasi

\subsection{Pembahasan}

Setelah melakukan analisis sesuai dengan kebutuhan maka didapatkan beberapa hasil yaitu rancangan struktur sistem, rancangan database, dan rancangan Mockup tampilan aplikasi. Semua rancangan dapat dilihat pada berikut ini 
A. Struktur system

Setelah melakukan Analisis kebutuhan aplikasi maka dibuatlah sebuah struktur sistem dengan rancangan sebagai berikut:

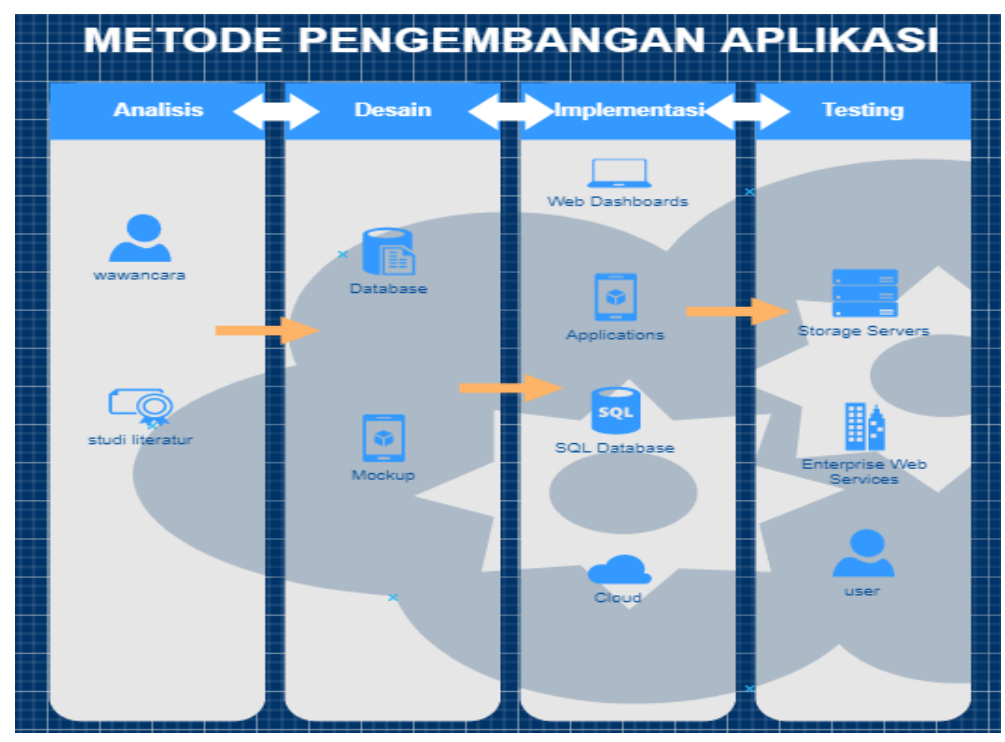

Gambar 2. struktur sistem

Struktur sistem terbagi menjadi empat tahapan yaitu yang pertama adalah analisis yang terdiri dari studi literatur dan wawancara, yang kedua adalah desain yang terdiri dari database dan mockup, yang ketiga adalah implementasi yang terdiri dari web dashboard, applikasi, SQL database, dan Cloud, lalu yang keempat adalah testing yang terdiri dari storage server, enterprise web Service, dan user.

B. Struktur database

Database yang digunakan adalah MySql dengan ketentuan tabel sebagai berikut

\begin{tabular}{|llll} 
& \# & Name & Type \\
$\square$ & 1 & id & int(150) \\
$\square$ & 2 & nama_lengkap & varchar(200) \\
$\square$ & 3 & nama_ & varchar(200) \\
$\square$ & 4 & password & varchar(200) \\
$\square$ & 5 & email & varchar(200) \\
$\square$ & 6 & level & varchar(200) \\
$\square$ & 7 & fakultas & varchar(200) \\
$\square$ & 8 & program_studi & varchar(200) \\
$\square$ & 9 & file & text \\
$\square$ & 10 & type & varchar(50) \\
$\square$ & 11 & angkatan & varchar(50) \\
$\square$ & 12 & tempat_lahir & varchar(50) \\
$\square$ & 13 & tanggal_lahir & date
\end{tabular}

Gambar 3. struktur database 
Struktur database terdiri dari beberapa table, yang setiap table nya menggunakan kolum dan field seperti gambar diatas.

C. Rancangan mockup

Setelah membuat rancangan struktur dan database, tahapan se-lanjutnya adalah membuat rancangan halaman user interface dalam bentuk mockup, dengan detail halaman berikut ini

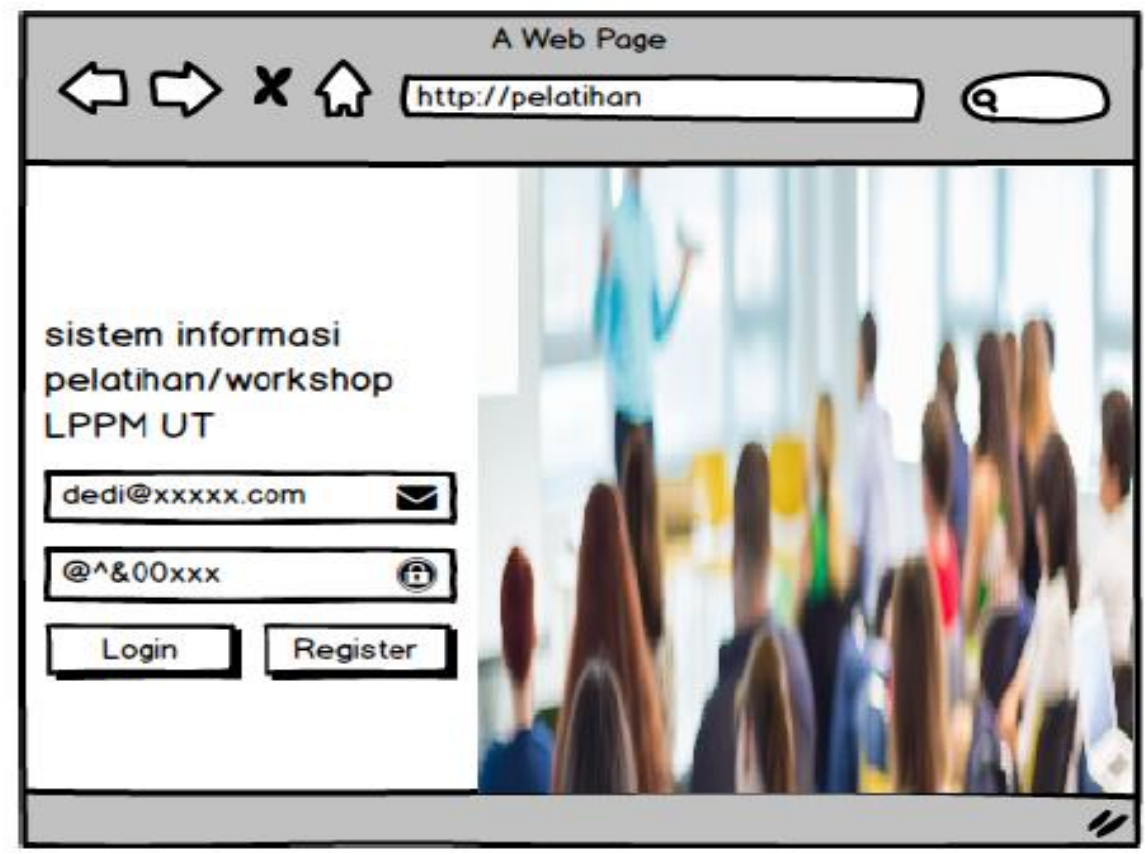

Gambar 4. mockup login form

Halaman login form berfungsi sebagai cara pengguna masuk kedalam sebuah sistem aplikasi, pengguna terdiri dari admin dan dosen.

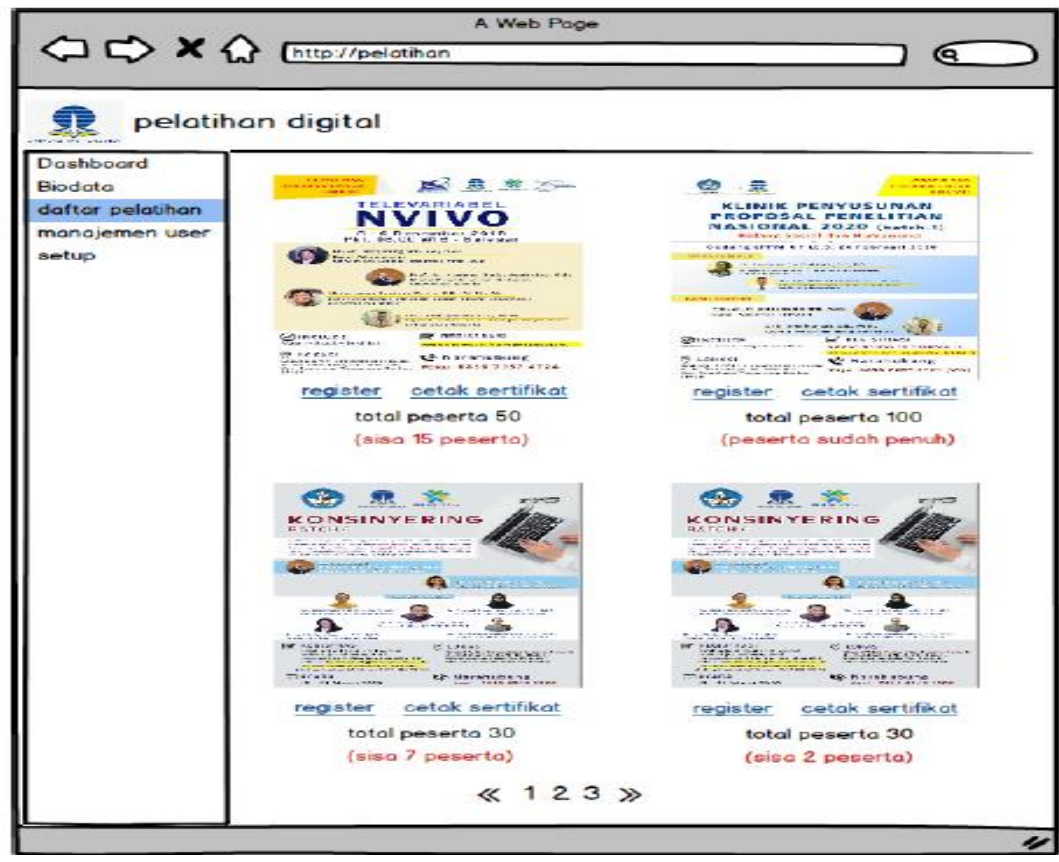

Gambar 5. mockup data pelatihan 
Mockup halaman daftar pelatihan berfungsi sebagai halaman yang memperlihatkan pelatihan mana saja yang diselenggaran oleh LPPM, hal ini membuat mudah pengguna untuk memilih pelatihan yang tersedia.

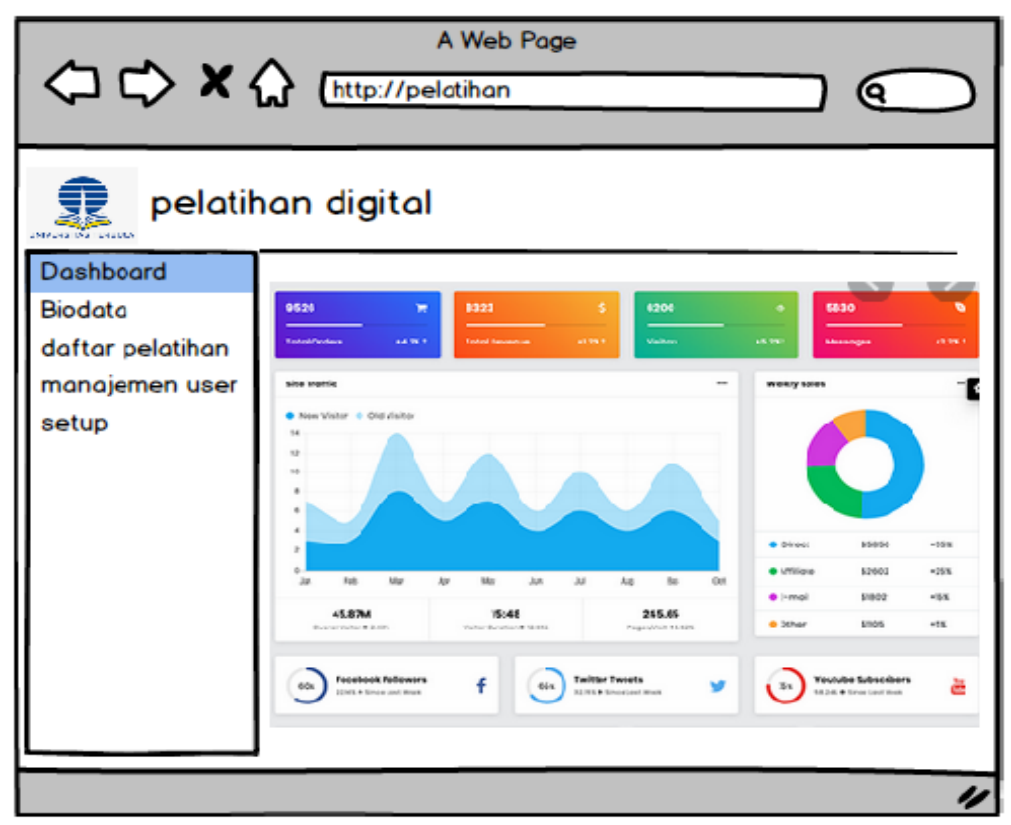

Gambar 6. mockup dashboard

Mockup halaman dashboard berfungsi sebagai rangkuman beberapa menu yang memudahkan pengguna untuk mendapatkan informasi.

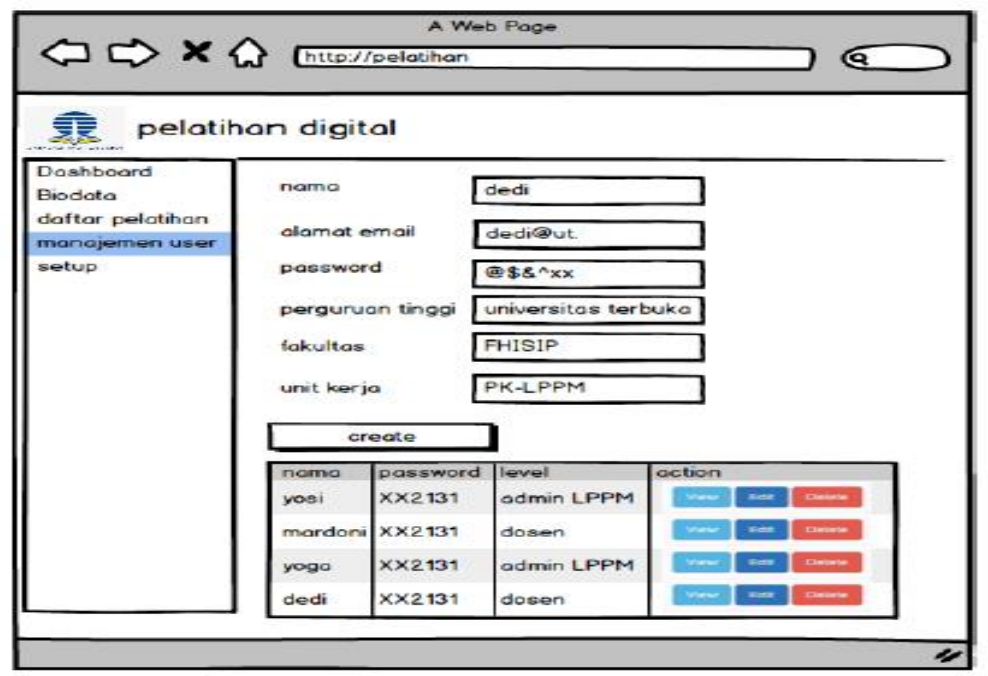

\section{Gambar 7. mockup manajemen user}

Mockup halaman manajemen user berfungsi untuk memudahkan admin LPPM dalam memanajemen user, dalam halaman ini ditambahkan juga menu edit, delete, dan view.

\section{KESIMPULAN}

Penelitian pada tahun pertama masih dalam tahap perancangan Mockup aplikasi. Sehingga pada tahun berikutnya dapat dikembangkan dalam bentuk implementasi program Website. Penelitian ini dapat memudahkan dan membantu pihak terkait dalam melakukan pembuatan e-sertifikat dan 
pelatihan berbasis digital (e-training) yang diselenggarakan di Pusat Penelitian dan Keilmuan (PPK) LPPM Universitas Terbuka.

\section{UCAPAN TERIMAKASIH}

Akhirnya, kami mengucap-kan terima kasih kepada Universitas Terbuka dan semua pihak yang mendukung selama penelitian ini berjalan.

\section{DAFTAR PUSTAKA}

Anjarkusuma. (2014). Penggunaan Aplikasi CMS Wordpress Untuk Merancang Website Sebagai Media Promosi pada Maroon Wedding Malang. 2(1), 63-69.

Ayu, F. (2018). Perancangan Sistem Informasi Pengolahan Data Praktek Kerja Lapangan (Pkl) Pada Devisi Humas Pt. Pegadaian. 2(2), 12-26.

Destiningrum, M., \& Adrian, Q. J. (2017). Sistem Informasi Penjadwalan Dokter Berbassis Web Dengan Menggunakan Framework Codeigniter ( Studi Kasus : Rumah Sakit Yukum Medical Centre ). 11(2), 30-37.

Icloudhost. (2017). Mengenal Apa itu Framework CodeIgniter.

Imbar, R. V. (2019). Pengembangan Konsep Kompensasi Dosen dengan mekanisme reward/punishment ditopang dengan konsep sustainabilitas keuangan dengan menggunakan Sistem Informasi. (Studi Kasus : Universitas X). Jurnal Teknik Informatika Dan Sistem Informasi, 5(2), 212-220. https://doi.org/10.28932/jutisi.v5i2.1739.

Rudika Harminingtyas. (2014). Analisis Layanan Website Sebagai Media Promosi, Media Transaksi Dan Media Informasi Dan Pengaruhnya Terhadap Brand Image Perusahaan Pada Hotel Ciputra Di Kota Semarang. 6(3), 37-57. 